\title{
The Psychological Capital Accumulation of Middle School Students in Quake-Stricken Wenchuan
}

\author{
Jian $\operatorname{Li}^{1} \&$ Lihui Huang ${ }^{1}$ \\ ${ }^{1}$ Institute of Education, Sichuan Normal University, Chengdu, China \\ Correspondence: Jian Li, Institute of Education, Sichuan Normal University, Chengdu, China. E-mail: \\ 48874756@qq.com
}

Received: August 3, 2014 Accepted: August 25, 2014 Online Published: October 30, 2014

doi:10.5539/ass.v10n21p128 URL: http://dx.doi.org/10.5539/ass.v10n21p128

\begin{abstract}
The Wenchuan earthquake has brought huge trauma to people there. Up to now, the post-traumatic stress disorder (PTSD) of the middle school students in Wenchuan is still quite apparent. Psychological capital theory is a new theory based on Positive Psychology and Positive Organizational Behavior. Psychological capital, a positive psychological state, is a potential to overcome obstacles. The present study aimed at examining the impact of psychological capital accumulation on alleviating PTSD. A total of 737 middle school students from six schools in quake -stricken region were interviewed with the Psychological capital scale for Post disaster middle school student (PCS) and Post traumatic stress disorder self-rating scale (PTSD-SS). The results showed that the accumulation of psychological capital have positive correlation with alleviate stress disorder. The results implied that people with rich psychological capital can better deal with trauma, the cultivation of resilience should be emphasized in education.
\end{abstract}

Keywords: psychological capital, stress disorder after trauma, Wenchuan earthquake

\section{Introduction}

On $12^{\text {th }}$ May, 2008, The Wenchuan earthquake has brought huge trauma to people there. Up to now, it is rather distressing that the stress disorder of the middle school students in Wenchuan is still quite apparent. Students there have demonstrated typical symptoms of post-traumatic stress disorder (PTSD) such as flashbacks, intense reactions, avoidance behaviors. Some students still have painful memories of the earthquake, waking up from nightmares over collapsed buildings and deceased family members. Some are unwilling to talk about the $12^{\text {th }}$ May earthquake, trying to avoid mentioning it. Others are rather grieved about their deceased fellow students, feeling compunctions, having sleeping problems and easily going to rage.

Earthquake, as a trauma causing natural disaster, can easily cause various psychological troubles, of which post-traumatic stress disorder is most common. It will pose long-term negative impact on people's health, family relationship and social relations and even hidden risks for the development of the quake stricken areas. The troubled individuals need psychological recovery.

Psychological capital refers to a positive psychological state during the development of individuals. Psychological capital emerged from as early as in the literatures of economists like Goldsmith, Veum and Darity etc, who regarded psychological capital as individual's views toward life including his attitude toward life and his ethical orientation (Goldsmith, Veum, \& Darity, 1997). Goldsmith defined psychological capital as characteristics affecting productive force, which includes view on oneself, ethical orientation, self-esteem, working attitude and general view towards life. Letcher equalized psychological capital to five human characteristics. From a labor- economic perspective, Goldsmith and Veum tried to locate factors apart from labor market that can explain the wage differences. They did not give a clear definition of psychological capital, nor did they make it clear whether or not this psychological feature or attitude is positive or negative.

Seligman (2002) mentioned psychological capital in his work True Happiness. He held that all the positive psychological factors leading to positive behaviors could be counted as capital. However, it is Luthans and his colleagues (2002) that first defined psychological capital. They defined psychological capital as factors that are at centre of individual positivity. It manifests specifically as psychological state that are in line with positive organizational behavior standards. As can be seen, psychological capital is a brand new definition that is beyond 
the description of human capital and social capital. It can be developed so individuals can obtain competitive edge by purposely invest in and develop it. Later, Larsen, Luthans and Youssef (2007) revised the definition of psychological capital as a positive psychological state in the growth and development of individuals.

Scholars haven't reach agreement on the constituents of psychological capital. According to Goldsmith, psychological includes self-esteem and controlling point (Cole, 2006). Luthans and Youssef summarized four constituents: a. Self-efficacy: when facing challenges, one has confidence and is able to work hard to succeed. b. Optimism: having positive reasons for current and future success. c. Hope: being persistent, one can adjust means to achieving objectives when necessary. $d$. Resilience: when in plight and troubled by problems, one can persevere, recover rapidly and go further to succeed (Luthans, 2005). However, in fact, as an assembly of lots of capabilities, psychological capital is more than just these four above-mentioned capabilities, which should include some potential psychological capital, for example, creativity, wisdom, subjective happiness and humor.

The measurement of psychological capital is relatively stable and concentrated. Most of researches combined effective dimensional scales. Researchers devised, researched and proved a large numbers of tools to measure self-efficacy, hope, optimism, resilience and other potential positive psychological concepts. The current representative scales are psychological capital questionnaire (PCQ), the Chinese version of which can be found in 24 psychological capital scale translated by Dr.Li Chaoping. But they have focused on normal society and human resource areas.

Psychological capital theory is a new one founded on positive psychology and positive organizational behavior, aimed at researching how to make people reach best conditions and cultivate and tap potentials.

Its application has broad areas in organization and the research results have proved its positive effects on individual and organization too. Veum, Goldsmith and Darity researched on the direct and indirect effects of psychological capital on employees' salary. The research shows that the psychological capital, production rate and salary of employees are remarkably and positively correlated. Compared with human resource capital, psychological capital has greater impact on the employees' salary. Luthans and his colleagues also researched on the impact of psychological capital on working attitude, which shows that the psychological capital, working attitude and satisfaction over organization are also remarkably correlated. On the other hand, compared with social capital, psychological capital apparently affects employees' working attitude. Employees 'psychological capital is negatively correlated with voluntary turnover (Luthans, Youssef, \& Avolio, 2008).

As psychological capital in nature is a potential that can be developed and accumulated, people with rich psychological capital can better ward off trauma (Luthans \& Jensen, 2005). The present study hypothesized that the accumulation of psychological capital has positive impact on alleviating PTSD.

\section{Methods}

\subsection{Participants}

Stratified sampling was adopted. Investigations were conducted in students from three middle schools and three high schools which are separately randomly selected in extremely hard-hit region, hard-hit region and ordinarily-hit region. They are Qiyi senior vocational school of Beichuan County, Yongchang Middle School of Beichuan Country, the First Middle school of Hanyuan County, Ya'an city, the First Affiliated Middle School of Sichuan Normal University, The No.2 Middle School of Zizhong County, Neijiang City. A total of 737 available responses were received out of an eligible sample of 800 , representing a $90 \%$ response rate.

Table 1. The distribution of 737 participants

\begin{tabular}{|c|c|c|c|c|c|c|c|c|c|c|}
\hline \multirow{2}{*}{ sort } & \multicolumn{2}{|c|}{ gender } & \multicolumn{4}{|c|}{ nation } & \multicolumn{3}{|c|}{ region } & \multirow[t]{2}{*}{ total } \\
\hline & male & female & Han & Tibetan & Qial & else & $\mathrm{O}$ & & $\mathrm{EH}$ & \\
\hline $\mathrm{n}$ & 286 & 451 & 521 & 51 & 153 & 12 & 194 & 223 & 320 & 737 \\
\hline$\%$ & 38.8 & 61.2 & 70.7 & 6.9 & 20.8 & 1.6 & 26.3 & 30.3 & 43.4 & 100 \\
\hline
\end{tabular}

Note. $\mathrm{OH}=$ ordinarily-hit; $\mathrm{HH}=$ hard-hit; $\mathrm{EH}=$ extremely hard-hit.

\subsection{Tools}

\subsubsection{Psychological Capital Scale for Post Disaster Middle School Student}

Psychological capital scale (PCS) for Post disaster middle school student (Li, 2013) was adopted, which include 25 questions, measuring five factors, namely self-efficacy, optimism, hope, resilience and gratitude. Its Cronbach's $\alpha$ coefficient is 0.91 , split-half reliability coefficient is $0.86(\mathrm{Li}, 2013)$. 


\subsubsection{Post Traumatic Stress Disorder Self-Rating Scale (PTSD-SS)}

PTSD-SS is regarded as a fairly good measurement tool of post- trauma stress disorder. Of its 24 questions, Cronbach's $\alpha$ coefficient is 0.92 , split-half reliability coefficient is 0.95 (Liu, 1998). There are three factors in PTSD-SS: reoccurrence/avoidance symptoms, psychological malfunction/ function damage, emotional numbness/nervousness and sensitivity. Each question was graded from 1-5. Total score $\geq 50$ indicates post trauma distress disorder, 50-59 common and 60 above serious. PTSD-SS can be used to screen the post trauma stress disorder.

\section{Results}

\subsection{Scores of PCS}

Descriptive statistical results of demographic variables for the total score and each factor can be found in table 2 . Multi-factor analysis of variance results was conducted, and the significant results can be found in table 3 .

Table 2. Test scores of PCS

\begin{tabular}{|c|c|c|c|c|c|c|c|c|}
\hline & & $\mathrm{n}$ & Total scores & self-efficacy & resilience & optimism & hope & gratitude \\
\hline \multirow{2}{*}{ gender } & male & 286 & $99.15 \pm 18.50$ & $30.33 \pm 7.46$ & $22.41 \pm 5.31$ & $11.25 \pm 3.04$ & $15.69 \pm 3.19$ & $19.69 \pm 3.69$ \\
\hline & female & 451 & $101.90 \pm 17.42$ & $30.37 \pm 6.68$ & $22.72 \pm 5.11$ & $11.50 \pm 2.82$ & $16.48 \pm 2.96$ & $19.98 \pm 3.70$ \\
\hline \multirow{4}{*}{ nation } & Han & 521 & $100.34 \pm 17.99$ & $30.57 \pm 7.02$ & $22.72 \pm 5.17$ & $11.60 \pm 2.90$ & $16.35 \pm 3.05$ & $19.93 \pm 3.67$ \\
\hline & Tibetan & 51 & $105.12 \pm 15.77$ & $32.94 \pm 6.15$ & $22.35 \pm 4.48$ & $12.33 \pm 2.45$ & $16.65 \pm 2.60$ & $20.84 \pm 3.75$ \\
\hline & Qiang & 153 & $93.29 \pm 16.50$ & $28.16 \pm 6.50$ & $20.39 \pm 5.04$ & $10.42 \pm 2.80$ & $14.88 \pm 2.99$ & $19.44 \pm 3.71$ \\
\hline & else & 12 & $101.67 \pm 21.01$ & $30.58 \pm 9.21$ & $24.25 \pm 5.85$ & $11.67 \pm 3.63$ & $16.75 \pm 3.67$ & $18.42 \pm 3.92$ \\
\hline \multirow{6}{*}{ grade } & 7 & 115 & $96.77 \pm 23.56$ & $30.34 \pm 7.67$ & $22.87 \pm 5.56$ & $11.50 \pm 2.75$ & $16.11 \pm 3.00$ & $19.53 \pm 3.65$ \\
\hline & 8 & 152 & $99.52 \pm 16.09$ & $30.24 \pm 6.45$ & $21.99 \pm 5.19$ & $11.14 \pm 2.96$ & $15.69 \pm 3.02$ & $20.51 \pm 3.70$ \\
\hline & 9 & 153 & $98.72 \pm 17.58$ & $30.14 \pm 7.17$ & $22.22 \pm 5.49$ & $11.49 \pm 3.00$ & $15.81 \pm 3.31$ & $19.11 \pm 3.49$ \\
\hline & 10 & 170 & $97.05 \pm 17.09$ & $29.55 \pm 6.94$ & $21.18 \pm 4.87$ & $11.06 \pm 3.02$ & $15.70 \pm 3.28$ & $19.55 \pm 3.81$ \\
\hline & 11 & 101 & $100.81 \pm 13.56$ & $29.37 \pm 6.65$ & $22.85 \pm 4.72$ & $11.64 \pm 2.83$ & $16.98 \pm 2.56$ & $19.97 \pm 3.70$ \\
\hline & 12 & 46 & $110.96 \pm 14.61$ & $34.71 \pm 5.90$ & $24.09 \pm 4.77$ & $12.56 \pm 2.32$ & $17.44 \pm 2.06$ & $22.16 \pm 2.91$ \\
\hline \multirow[t]{3}{*}{ region } & $\mathrm{OH}$ & 194 & $107.38 \pm 18.69$ & $32.78 \pm 8.21$ & $25.81 \pm 5.44$ & $12.04 \pm 3.19$ & $16.59 \pm 3.49$ & $20.16 \pm 3.94$ \\
\hline & $\mathrm{HH}$ & 223 & $102.70 \pm 18.19$ & $30.19 \pm 6.45$ & $23.42 \pm 5.01$ & $12.22 \pm 2.78$ & $16.96 \pm 2.79$ & $29.91 \pm 3.45$ \\
\hline & $\mathrm{EH}$ & 320 & $96.50 \pm 16.39$ & $29.40 \pm 6.40$ & $20.75 \pm 4.73$ & $11.03 \pm 2.73$ & $15.43 \pm 2.89$ & $19.88 \pm 3.71$ \\
\hline \multicolumn{2}{|c|}{ total } & 737 & $99.23 \pm 17.86$ & $30.23 \pm 6.99$ & $22.23 \pm 5.20$ & $11.41 \pm 2.91$ & $16.07 \pm 3.08$ & $19.87 \pm 3.69$ \\
\hline
\end{tabular}

Note. $\mathrm{OH}=$ ordinarily-hit; $\mathrm{HH}=$ hard-hit; $\mathrm{EH}=$ extremely hard-hit

Table 3. Multi-factor analysis of variance results $(F$,

\begin{tabular}{lllllll}
\hline & Total scores & self-efficacy & resilience & optimism & hope & gratitude \\
\hline grade & $7.17^{* * *}(0.56)$ & $6.36^{* * *}(0.46)$ & $2.94^{*}(0.06)$ & $3.37^{* *}(0.07)$ & $3.98^{* *}(0.40)$ & $3.91^{* *}(0.04)$ \\
region & $4.48^{*}(0.06)$ & $2.21(0.03)$ & $8.99^{* * *}(0.48)$ & $3.14^{*}(0.05)$ & $3.26^{*}(0.05)$ & $0.12(0.009)$ \\
grade*region & $1.62(0.04)$ & $2.70^{* *}(0.09)$ & $1.85(0.02)$ & $0.89(0.02)$ & $0.88(0.02)$ & $2.11^{*}(0.05)$ \\
gender*region & $0.95(0.02)$ & $0.15(0.01)$ & $0.82(0.02)$ & $0.73(0.002)$ & $0.53(0.002)$ & $5.62^{* *}(0.05)$ \\
gender*grade*region & $2.07^{*}(0.05)$ & $1.44(0.04)$ & $2.30^{*}(0.05)$ & $1.22(0.03)$ & $1.54(0.03)$ & $0.91(0.01)$ \\
\hline
\end{tabular}

Note. ${ }^{*}=p<0.05, \quad{ }^{* *}=p<0.01,{ }^{* * *}=p<0.001$.

The above results showed that such variables as grade and region (the type of the quake-hit regions) have main effect on the total score and the score of each factor. The multiple comparison methods were adopted for further analysis.

Table 4. Multiple comparison of grade difference on total scores and factor scores

\begin{tabular}{|c|c|c|c|c|c|c|c|}
\hline \multirow{2}{*}{\multicolumn{2}{|c|}{ grade }} & \multicolumn{6}{|c|}{ average difference } \\
\hline & & Total scores & self-efficacy & resilience & optimism & hope & gratitude \\
\hline \multirow[t]{4}{*}{12} & 10 & $15.47^{\text {*** }}$ & $6.69^{* * *}$ & $2.47^{*}$ & $1.25^{*}$ & $1.98^{* *}$ & $3.09^{* * * * *}$ \\
\hline & 11 & $9.87^{*}$ & $6.19^{* * *}$ & & & & \\
\hline & 7 & $12.80^{* * *}$ & $5.71^{* * *}$ & & $1.75^{* *}$ & $2.03^{* *}$ & $2.66^{* *}$ \\
\hline & 8 & $8.87^{*}$ & $3.54^{*}$ & & & & \\
\hline
\end{tabular}

The results of multi-comparison test showed that the details of grade difference and region difference on PCS scores. The total score and the score of each factor of the 12th grade students are significantly higher than those of the $10^{\text {th }}$ grade students. The total score and the score of self-efficacy, optimism, hope and gratitude of the 12th 
grade students are higher than those of the 7th grade students. The total score and the score of self- efficacy of the 12th grade students are significantly higher than those of the 8th and 11th grade students. There are no significant differences among other grades. The total score and the score of each factor (except gratitude) of students from extremely hard-hit regions are significantly lower than those of the ones from ordinarily-hit regions. The total score and the score of resilience, optimism and hope of students from extremely hard-hit regions are notably lower than those of the ones from hard-hit regions. The score of resilience of students from hard-hit regions are strikingly lower than that of students from ordinarily-hit regions.

Table 5. Multiple comparison of region difference on total scores and factor score

\begin{tabular}{|c|c|c|c|c|c|c|c|}
\hline \multirow[t]{2}{*}{ region } & & \multicolumn{6}{|c|}{ average difference } \\
\hline & & Total scores & self-efficacy & resilience & optimism & hope & gratitude \\
\hline $\mathrm{EH}$ & $\mathrm{OH}$ & $-10.88^{* *}$ & $-3.38^{* *}$ & $-5.06^{*}$ & $-1.01^{*}$ & $-1.16^{*}$ & \\
\hline & $\mathrm{HH}$ & $-6.20^{*}$ & & $-2.66^{* *}$ & $-1.18^{*}$ & $-1.53^{* *}$ & \\
\hline $\mathrm{HH}$ & $\mathrm{OH}$ & & & $-2.39^{*}$ & & & \\
\hline
\end{tabular}

Note. $\mathrm{A} . \mathrm{OH}=$ ordinarily-hit; $\mathrm{HH}=$ hard-hit; $\mathrm{EH}=$ extremely hard-hit.

B. ${ }^{*}=p<0.05, \quad{ }^{* *}=p<0.01, \quad{ }^{* * *}=p<0.001$.only the significant difference were showed in table 5 .

\subsection{Correlation Analysis of the Scores of PCS and PTSD-SS}

The results of correlation analysis showed significantly negative correlation between PCS and PTSD-SS, especially between resilience and PTSD-SS. It revealed that the students getting high score at psychological capital tend to score lower at PTSD-SS, especially in resilience.

Table 6. Correlation analysis of PCS and PTSD-SS

\begin{tabular}{|c|c|c|c|c|c|c|c|c|c|}
\hline & \multicolumn{4}{|c|}{ Scores of PTSD-SS } & \multicolumn{5}{|c|}{ Scores of PCS } \\
\hline & total scores & $\begin{array}{l}\text { reoccumrence/avoidance } \\
\text { symptoms }\end{array}$ & $\begin{array}{l}\text { psychological } \\
\text { malfunction/ } \\
\text { functiondamage }\end{array}$ & $\begin{array}{l}\text { emotional } \\
\text { numbnessinervousness } \\
\text { andsensitivity }\end{array}$ & total scores & self-efficacy & resilien & optimisn & hope \\
\hline \multicolumn{10}{|c|}{$\begin{array}{l}\text { reoccumence/avoidance } 0.96^{* *} \\
\text { symptoms }\end{array}$} \\
\hline $\begin{array}{l}\text { psychological } \\
\text { malfunction/ function } \\
\text { damage }\end{array}$ & $0.89^{* *}$ & $0.76^{* *}$ & & & & & & & \\
\hline $\begin{array}{l}\text { emotional } \\
\text { numbness/nervousness } \\
\text { and sensitivity }\end{array}$ & $0.84^{* *}$ & $0.77^{* *}$ & $0.68^{* *}$ & & & & & & \\
\hline total scores of PCS & $-0.32^{* * r}$ & $-0.32^{* * *}$ & $-0.31^{* *}$ & $-0.27^{* * *}$ & & & & & \\
\hline self-efficacy & $-0.12^{* *}$ & $-0.11^{* *}$ & $-0.15^{* *}$ & -0.06 & $0.87^{* *}$ & & & & \\
\hline resilience & $-0.35^{* *}$ & $-0.34^{* * *}$ & $-0.32^{* *}$ & $-0.29^{* * *}$ & $0.82^{* *}$ & $0.60^{* *}$ & & & \\
\hline optimism & $-0.16^{* * *}$ & $-0.16^{* * *}$ & $-0.13^{* *}$ & $-0.14^{* * *}$ & $0.77^{* *}$ & $0.59^{* *}$ & $0.62^{*}$ & & \\
\hline hope & $-0.18^{* * *}$ & $-0.16^{* *}$ & $-0.16^{* *}$ & $-0.16^{* *}$ & $0.80^{* *}$ & $0.61^{* *}$ & $0.59^{*}$ & $0.64^{* * *}$ & \\
\hline gratitude & $-0.15^{* *}$ & $-0.14^{* *}$ & $-0.15^{*}$ & $-0.12^{* * *}$ & $0.42^{* * *}$ & $0.22^{* * *}$ & $0.20^{*}$ & $0.18^{* * *}$ & $0.27^{* * *}$ \\
\hline
\end{tabular}

\section{Discussion}

\subsection{Psychological Capital Is a Potential inside Human to Overcome Difficulties}

Humanistic psychology emerged in the United States in 1950s, which is based upon human and human life and represented by Maslow and Rogers etc. humanistic psychology advocates the study of human nature, human potential, human experienced, human value and human creativity. It can be regarded as a breakthrough of no human factor in former psychological studies. Its viewpoints include the following three points. First, it insists on starting from human experience, stressing human integrity, distinctiveness and independence. Second, with human potential as the basis, it emphasizes the unlimited potential inside human body, which can bring about possibility for human development and bright future. Third, taking human value and character development as key, it emphasizes taking self-selection, self-fulfillment and healthy personality as life goals. At a time when sci-tech rationality is booming, emphasizing human, healthy human personality and life value, humanistic 
psychology not only epitomize caring educational theories but also provides a broad space and a macro theoretical perspective for the healthy and full life development.

Based on the theory of human nature, humanistic psychology believes that human nature is originally good and positive. It holds that human beings can spur their potential under the influence of internal proneness and their basic need is determined by their potential. As long as a proper climate is given, anyone can educate himself well, tap his potential and improve his personality.

Psychological capital is an inexhaustible force inside everyone's body and the power engine for sustained development. Human life is full of unlimited possibilities. Life indeed is in the incessant process of renewing and constructing. As a matter of fact, each of us has potential to overcome difficulties to achieve self development. After gusty natural disasters, life education, which highly values life caring, aims to tap and utilize the potential of the student, stimulate them to accumulate psychological capital, warding off psychological trauma caused by natural disasters and dispersing the ensuing confusion in life.

\subsection{Resilience, as the Most Important Factor of Psychological Capital, Is the Pivotal in Overcoming Post-Trauma Stress Disorder}

In 1972, Lats found after research individual variations of the damage to psychological behavior in children imposed by negative child life environment (Masten \& Reed, 2002). The individual variations are called resilience, the translation of which is not necessarily the same in China, Hongkong and Taiwan. Previous research only emphasized self recovery in the wake of trauma and distress. As the research continued, it not only means that individuals can recover from trauma and distress and persist under stress, but also emphasize the development and rejuvenation. I chose "Ni Kang Li" as the interpretation of resilience because it is widely and popularly used in studies on risks and disasters. The present research also focuses on life education after sudden natural disasters. Moreover, Forlan from US regarded as the focal points in the study of resilience the anticipation and feeling before disasters and how to adjust, adapt and recover resilience after disasters. As an internal feature of social ecological system, resilience stresses the ability to adapt to external difficulty, stress and impact instead of the results brought about by external impact. What is more, resilience is not equal to stability. Resilience emphasizes the dynamic process of recovering to the original or even better state after external impact, or the upgrading of resilience. This also conforms to my advocacy of amassing psychological capital represented by resilience.

From table 6, we can see that the total scores of PTSD are negatively correlated with factors of psychological capital. The negative correlation between resilience and the total score PTSD is 0.36 . It is so remarkable as to demonstrate that resilience may be a key factor for preventing individuals from harm caused by sudden natural disasters and a strong force for recovery and growth. When damaging factors such as disasters come, resilience will help individuals to resist pressure and avoid trauma. Meanwhile it will enable them to quick recover and achieve outstanding development.

\subsection{The Five Factors of Psychological Capital Are Closely Correlated, with the Former Four Acting as the} Buttress of Resilience

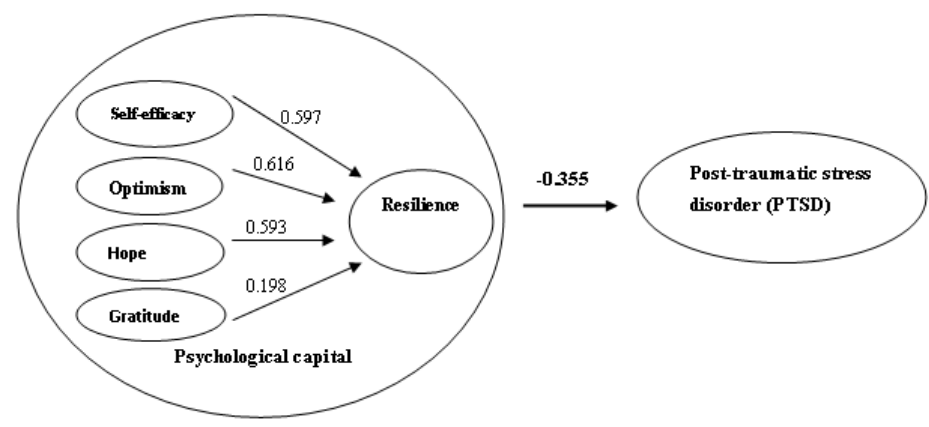

Figure 1. The relationship between psychological capital and PTSD

The correlation between resilience and the other four factors can be seen in figure 1 . Resilience is significantly positively correlated with self efficacy, optimism, hope and gratitude, with a coefficient of $0.597,0.616,0.593$ and 0.198 respectively. Except that of gratitude, the other three coefficients are above median level, meaning the 
accumulation of other factors in psychological capital can provide forceful support to resilience and are conducive to the accumulation of resilience itself.

\subsection{Stronger Cultivation of Resilience Is Needed in Education}

As a born potential, resilience are dynamic factors that protect individuals in the process of trauma recovery. Resilience is the core of psychological capital. When things go smoothly, it is dormant. When misfortunes such as disasters, troubles, setbacks and crisis arise, resilience is then activated. So powerful, it will make individuals into a spring and help them face trouble, fight against disasters and tide over difficulties. Although it is congenital, it is mainly the result of internal and external factors after one's birth. Therefore, acquired education and training can promote resilience. We can say that resilience can be developed and accumulated.

Related researches have showed that the formation of resilience is attributed to multiple factors: congenital factors, one's life and study experience in early years and one's life and study experience after crises and disasters. So it is obvious that family life and family education in one's early years does have impact on the formation of resilience. Speaking of family, we should proceed from the need of children's life, giving them more care and love, creating a stable environment for psychological development. That is conducive to the cultivation of resilience. At the same time, frustration education should carried out and refrain from over doting. For examples, we should limit the amount of children's pocket money, urging them to build the awareness to manage money. It is better not to solve the problems our children meet in life and should cultivate their ability to solve by themselves so as to make them more independent. The experience from and reflection on crises and disasters can also step up with resilience. For instance, the people in Wenchuan received assistance and feel the care from across the country soon after the earthquake. The partner mode of reconstruction also makes the victims feel the warmth of the big socialist family. From the reflection on the nation's dealing with the crisis, the victims feel the care for their lives, thus reinforcing their resilience. The victims from Qing chuan County show their determination that "we will do our own things with our own efforts and "with our hands, we can overcome huge difficulties."

Resilience, on the other hand, is the combination of capabilities, resource, knowledge and skills accumulated for a long time, including positive psychological features like self -efficacy, optimism, hope and gratitude etc., whose development could buttress that of resilience. For that reason, when cultivating resilience in school, equal importance should be placed on that of the constituents of psychological capital. In the wake of disasters, schools should inspire the students to discover the fortune out of misfortune and outside systematic support and resource so that the students can feel being loved and cared. On that basis, we should help students to utilize their own inner power to increase their confidence, stimulating their self-efficacy. As a result, with confidence and optimism, the students will take predicament only as a setback and will not be thrashed by troubles ensued the disasters. Curriculum that cultivating other constituents of psychological capital through cultivating of self-efficacy will undoubtedly increase the resilience of students, which we should pay attention to during the process of promoting life education.

Besides, schools should carry out various activities and give positive assessment on the efforts and achievements of the students, enabling them to experience sense of achievements from success in those activities. We should try to make them believe that although disasters may bring about environmental change, they can adopt to it quickly and turn impossibility into possibility. Thus their self efficacy and hope are raised, so does their resilience. We should also step up our psychological guidance and cultivate their self-healing capability by telling them that disasters like earthquake cannot be avoided because they are out of the control of humans and cannot be predicated due to limited knowledge of humans. In this way, we could help young people have an objective knowledge of disasters and alleviate their pains of failing to help others amidst disasters so as to reinforce their self-controlling capabilities and their resilience.

\section{Acknowledgements}

This is a research finding based on three funded projects: 1) The cultural remodeling and harmonious society constructing in Wenchuan earthquake area funded by The major program of National Social Science Fund (Project No. 08\&ZD007). 2) The change in life values of people from earthquake stricken area funded by The MOE (Ministry of Education in China) Project of Humanities and Social Sciences (Project No. 10YJCZH048). 3) Life education of response to quake funded by The major program of Sichuan Normal University.

\section{References}

Bandura, A. (1991). Social Cognitive Theory of Self-regulation. Organizational Behavior and Human Decision Processes, 50(2), 248-287. http://dx.doi.org/10.1016/0749-5978(91)90022-L 
Goldsmith, A. H., Veum, J. R., \& Darity, W. J. (1997). The Impact of Psychological and Human Capital on Wages. Economic Inquiry, 35, 815-829. http://dx.doi.org/10.1111/j.1465-7295.1997.tb01966.x

Li, J. (2013). Effect of the life education on posttraumatic stress disorder: An empirical study, examples from middle schools in quake stricken Wenchuan areas. (Unpublished doctoral dissertation). Southwest University, Chongqing, China.

Liu, X. C., Ma, D. D., \& Liu, L. Q. (1998). Development of the post-traumatic stress disorder self-rating scale and reliability and validity. Chinese Journal of Behavioral Medical Science, 2, 93-96.

Luthans, K. W., \& Jensen, S. M. (2005). The Linkage between Psychological Capital and Commitment to Organizational Mission: A Study of Nurses. Journal of Nursing Administration, 35(6), 304-310. http://dx.doi.org/10.1097/00005110-200506000-00007

Luthans, F., Youssef, C. M., \& Avolio, B. J. (2007). Psychological capital: Developing the human competitive edge (pp. 112-118). Oxford, UK: Oxford University Press.

Seligman, M. E. P. (2002). Authentic Happiness (pp. 213-221). NewYork: Free Press.

Snyder, C. R. (2002). Hope theory: Rainbows in the mind. Journal of Psychological Inquiry, 13(4), 249-275. http://dx.doi.org/10.1207/S15327965PLI1304_01

\section{Copyrights}

Copyright for this article is retained by the author(s), with first publication rights granted to the journal.

This is an open-access article distributed under the terms and conditions of the Creative Commons Attribution license (http://creativecommons.org/licenses/by/3.0/). 